\title{
How reliable is the habitat suitability index as a predictor of great crested newt presence or absence?
}

\author{
Andrew S. Buxton ${ }^{1,2}$, Hannah Tracey ${ }^{3}$ \& Nick C. Downs ${ }^{3,4}$ \\ ${ }^{1}$ Durrell Institute of Conservation and Ecology, School of Anthropology and Conservation, University of Kent, Marlowe Building, Canterbury, Kent, CT2 7NR, UK \\ ${ }^{2}$ Amphibian and Reptile Conservation Trust, 744 Christchurch Road, Boscombe, Bournemouth, Dorset, BH7 6BZ, UK \\ ${ }^{3}$ Arcadis, 2 Glass Wharf, Bristol, BS2 OFR, UK \\ ${ }^{4}$ University of Bristol, School of Biological Sciences, Woodland Road, Bristol, BS8 1UG, UK
}

\begin{abstract}
The application of a habitat suitability index (HSI) assessment to predict the use of ponds by great crested newts (Triturus cristatus) is commonly used in association with distribution and monitoring projects. Such projects are often used to inform development and planning decision making. However, this type of assessment is frequently misused, and misinterpreted. We used a large, commercially collected environmental DNA (eDNA) survey for great crested newt pond occupancy (489 ponds) to; (1) assess whether it is appropriate to use low HSI scores to rule out occupancy, (2) discuss the use of high HSI scores to identify ponds of high importance for the species and, (3) explore the eDNA detection method. We conclude that there is no evidence to support ruling out pond occupancy based on low HSI scores. However, the conventional view that ponds with $\mathrm{HSI}$ scores above 0.7 are of high importance to great crested newts is somewhat supported by the data. Both eDNA and direct observational survey methodologies suffer from sampling error and these need to be acknowledged in the analysis of large data sets.
\end{abstract}

Keywords: Great crested newt, habitat suitability index, HSI, Triturus cristatus, environmental DNA, presence absence survey

$\mathrm{M}$ echanisms for quickly estimating the suitability of habitat for a particular species in the field are commonplace in ecology. These can be simply based on expert opinion or formalised via standardised assessments such as habitat suitability indexes (U.S. Fish and Wildife Service, 1981). However, data from such assessments can be difficult to interpret which can lead to misuse.

Great or Northern crested newts (Triturus cristatus) are the most widespread of the Triturus super-species consisting of seven closely related species, with a distribution from the UK and France in western Europe across to the Ukraine and southern Russia in the East (Wielstra et al., 2019). Within the UK, great crested newts are the largest of the three native newt species and occupy a wide variety of habitats. These include lowland river valleys with spring-fed ponds which do not flood (Inns, 2009), brownfield sites (Baker et al., 2011), broadleaved or mixed woodland, undisturbed grassland (Jehle \& Arntzen, 2000; Skei et al., 2006), and urban fringe (Harper et al., 2019) as well as other habitat types. As a semi aquatic amphibian both aquatic and terrestrial habitat quality is highly important in supporting a viable population, a factor which is often overlooked.

Within Europe, the species is protected by various national and international legal instruments including the
Convention on the Conservation of European Wildlife and Natural Habitats 1979, and the Conservation of Habitats and Species (Amendment) (EU Exit) Regulations 2019. Within the UK, the species is listed under the Conservation of Habitats and Species Regulations 2017 (as amended), the Wildlife and Countryside Act 1981 (as amended) in England and Wales, and the Conservation (Natural Habitats, \&c.) Amendment (Scotland) Regulations 2019 in Scotland. This legislation means that a greater level of effort is applied to distribution assessments for the great crested newt than most species. Assessments of impact, for example for land use change, are required (English Nature, 2001), while national assessments of the species distribution and conservation status also require regular reporting.

Habitat suitability assessments have been used for decades, with many developed for a wide variety of species in the 1980s (U.S. Fish and Wildlife Service, $1976,1980,1981)$, some examples being for the muskrat (Ondatra zibethicus) (Allen \& Hoffman, 1984) and the Brown Trout (Salmo trutta) (Wesche et al., 1987). The great crested newt Habitat Suitability Index (HSI) was developed by Oldham et al. (2000) to assess the potential quality of a pond for great crested newts. It has been amended and simplified since (ARG UK, 2010). Although it was first developed for use in the UK, it has 
since been used widely across Europe (Unglaub et al., 2015). The assessment involves the rapid categorisation of the habitat using a number of variables, with minimal equipment, and interpretation can vary widely between individual surveyors. Additionally, the final calculation treats each variable with equal weighting, an assumption that is unlikely to reflect the ecological importance of the different variables. Interpretation of the HSI therefore needs to be treated with a certain level of caution. The great crested newt HSI is used by some practitioners as an indicator of newt presence or absence: this is potentially a misinterpretation of its predictive power.

It is a requirement within the UK to undertake an HSI assessment alongside any great crested newt surveys where the results will be used to inform planning conditions. However, it is clear that the HSI should not replace direct surveys for the species (Natural England, 2015). HSI assessments are key components of both the national monitoring programme (Pondnet, 2013), and the various monitoring schemes for recently launched District Level Licencing (DLL) approaches to great crested newt conservation (Burgess, 2020; Nature Space Partnership, 2019). Nonetheless, the way in which the $\mathrm{HSI}$ is interpreted in these settings is not always robust or supported by evidence. In terms of habitat creation, an arbitrary HSI score of 0.7 has been assigned to generally indicate 'success'. Instances of using HSI scores that would be classed as 'Poor' or in some instances 'Below Average' as a justification to rule out further commercial survey work, have been brought to the attention of the authors.

In recent years surveys targeting environmental DNA (eDNA) have been developed as a cost-effective and rapid tool for the assessment of great crested newt pond occupancy (Biggs et al., 2014, 2015; Buxton et al., 2017; Rees et al., 2014). eDNA surveys target DNA that has been shed by the target organism and become suspended in the water column (Harper et al., 2018; Jane et al., 2015; Thomsen \& Willerslev, 2015). eDNA surveys have advantages over direct observational survey methods, in that they require only a single visit to a pond (Biggs et al., 2015). Surveys can be undertaken as lone workers and in daylight hours. Direct observational methodologies require several overnight visits using multiple methodologies and teams of people, to obtain a similar detection rate (Buxton et al., 2018; Sewell et al., 2010). As a result, eDNA analysis enables large-scale distribution assessments to be conducted with relative ease which were not previously possible (Biggs et al., 2015).

We examine whether the HSI is a good predictor of species occupancy, using a large-scale distribution assessment of the great crested newt in north-west England. Weanalyse the distribution of HSI results obtained for ponds occupied by great crested newts alongside those with no confirmed occupancy, and discuss the utility of the technique as a fine-scale predictor of species presence-absence. We examine the individual suitability index variables to determine the relative importance of each within the prediction of pond occupancy. We also make conclusions about the applicability of the eDNAbased occupancy information to large-scale commercial distribution assessments.

\section{METHODS}

\section{Site selection and protocols}

The ponds were surveyed as part of the ecological assessment process for the National Grid North West Coast Connections project, which aimed to install approximately $180 \mathrm{~km}$ of new powerline roughly parallel to the Cumbrian (UK) coastline. All ponds surveyed were within the linear area expected to be directly impacted by works (the order limits), plus a $500 \mathrm{~m}$ buffer either side. Ponds were initially identified via a detailed review of Ordnance Survey maps and high-resolution aerial imagery. The presence of these ponds in the field was checked during individual pond HSI surveys. Additional ponds were discovered from phase 1 habitat surveys of the entire order limits and $500 \mathrm{~m}$ buffer area. In total, 489 ponds were surveyed.

All field surveys adhered to strict biosecurity measures, following guidance from ARG UK (ARG UK, 2017). This comprised either using equipment for one site only, or cleaning, disinfecting and drying between sites. Footwear and vehicle wheels were also disinfected and dried between sites. In all cases, a disinfectant solution of Virkon ${ }^{\circledR}$ was used.

\section{eDNA surveys}

eDNA samples were collected from 464 ponds using sampling methodologies adopted for commercial analysis within the UK, as regulated by Natural England and described in Biggs et al. (2014). eDNA sample collection was undertaken during the great crested newt breeding season in 2015, 2016 or 2017. Each pond was sampled at twenty locations around the edge, where $30 \mathrm{~mL}$ of water were collected using a dipper and transferred to a Whirl$\mathrm{Pak}^{\circledR}$ self-standing sterile plastic bag. The composite sample from around the pond was homogenised and then subsampled to preserve $15 \mathrm{~mL}$ of sample in each of six $50 \mathrm{~mL}$ centrifuge tubes containing $1.5 \mathrm{~mL}$ of $3 \mathrm{M}$ sodium acetate solution and $33 \mathrm{~mL}$ of $99 \%$ ethanol. The samples were then analysed using quantitative PCR ( $\mathrm{PPCR}$ ) in a commercial laboratory following the methodology laid out in Biggs et al. (2015), using PCR primers and hydrolysis probe developed by Thomsen et al. (2012). All samples were assessed for both degradation and PCR inhibition using an internal positive control DNA introduced to both sample collection tubes prior to field collection, and at the qPCR stage.

Complexities associated with the survey schedule (for example land access restrictions or changing survey boundaries) resulted in direct observational surveys of 25 ponds without prior eDNA surveys.

\section{Direct observational surveys}

A subset of 103 ponds were subject to direct observational survey methods in addition to eDNA sampling, while 85 ponds were either surveyed using observational methods only or returned an inclusive eDNA survey result which was followed up with observational surveys. In addition to result confirmation, direct observational surveys were undertaken to obtain a population size class estimate (English Nature, 2001). A combination of bottle trapping, torchlight counts, hand searches for eggs and sweep 
netting for adults was undertaken following standard commercial methodologies for the UK (Cresswell \& Whitworth, 2004; English Nature, 2001; Griffiths \& Inns, 1998; Griffiths et al., 1996; Langton et al., 2001; Sewell et al., 2013).

\section{Habitat Suitability Index}

A HSI assessment was undertaken on each of the 489 ponds (Oldham et al., 2000). In total, ten habitat variables are recorded in the field, comprising geographic location, pond area, frequency of drying, water quality, pond shading, waterfowl presence, fish presence, pond density, the composition of the immediate terrestrial habitat and pond macrophyte cover. Each of these categories are assigned a value of between 0.01 and 1.0 with the geometric mean of the ten values taken to estimate the HSI of a pond for great crested newts. Overall HSI scores close to zero represent unsuitable habitat, while those closer to one represent optimal habitat (Unglaub et al., 2015). HSI categories were introduced by ARG UK advice note (ARG UK, 2010) as a way to help the interpretation of results, the categories were split so that approximately $20 \%$ of ponds fall within each of the five categories. These categories are 'Poor' (HSI =0-0.49), 'Below Average' ( $\mathrm{HSI}=0.5-0.59)$, 'Average' ( $\mathrm{HSI}=0.6-0.69)$, 'Good' (HSI=0.7-0.79) and 'Excellent' (HSI=0.8-1).

\section{Analysis}

Data from all occupancy assessment methods was pooled to generate naïve estimates for occupancy, with simple percentages used to compare occupancy when both eDNA and observational surveys had been conducted on the same water bodies. We compare the proportions of occupied and unoccupied ponds falling into each of the HSI categories.

We used a general linear model to assess whether there is a statistically significant difference between ponds with confirmed occupancy and those with no confirmed occupancy. We use a logistic regression to examine the effect that individual HSI covariates have on binary pond occupancy results from the eDNA and direct observational survey data. All continuous covariates were standardised prior to analysis. All data analysis was undertaken in $\mathrm{R}$ version 4.0.0 (R-Core Team, 2020) with the additional package glmulti (Calcagno \& de Mazancourt, 2010) to undertake logistic regression of all model combinations, and Akaike's information criterion (AIC) model selection. We then calculate the relative importance of each of the HSI covariates using the inbuilt Multimodal inference and assessed them as highly supported or somewhat support based on Marchetti et al. (2004).

\section{RESULTS}

\section{Naïve occupancy and detectability}

Sixty-four of the 489 ponds surveyed were found to be occupied by great crested newts, either through eDNA or direct observational surveys, give a naïve occupancy rate of 0.13 .

Occupancy data was generated using both eDNA and direct observational methods at 85 ponds. The results of the two methodologies concurred $76 \%$ of the time. In five cases ponds were found to be negative using eDNA, but great crested newts were identified using direct observation-based survey methods (naïve error rate of $6 \%$ ). Conversely, 15 of the 85 ponds were found to be positive using eDNA but this was not confirmed using observational methods, (naïve error rate of 18 $\%)$. Neither of these estimates take into account the potential for false positive eDNA results and they do not take into account instances where both methodologies may have missed the species, suggesting they are both underestimates.

\section{HSI results}

Mean HSI score of all ponds surveyed was found to be $0.64(95 \% \mathrm{Cl}=0.58-0.69)$, ranging from 0.19 to 0.98 $(N=489)$. Overall, 102 ponds $(20.86 \%)$ fell into the "Poor" category ( $\mathrm{HSI}<0.5), 88(18.00 \%)$ into the "Below Average" category ( $\mathrm{HSI}=0.5-0.59), 97$ (19.84\%) into the "Average" category (HSI = 0.6-0.69), 119 (24.34 \%) into the "Good" category (HSI = 0.7-0.79) and 83 (16.97\%) into the "Excellent" category (HSI > 0.8) (Fig. 1).

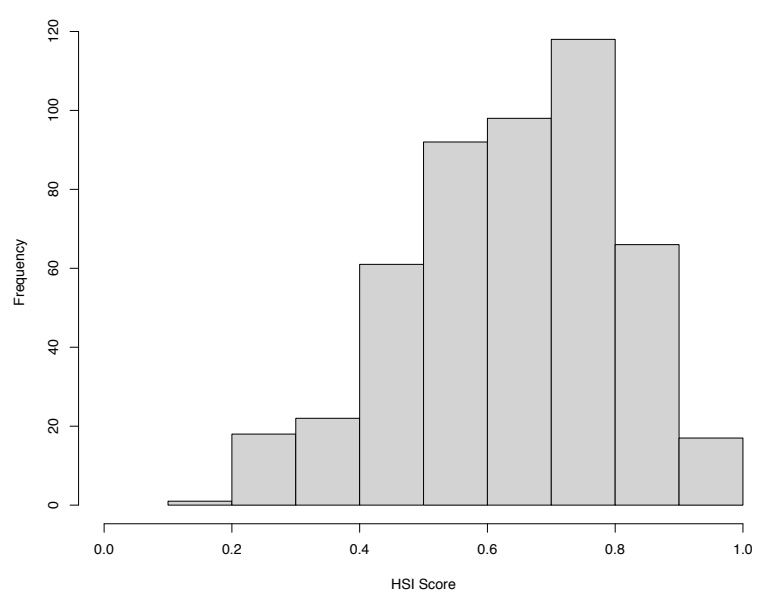

Figure 1. the distribution of HSI score for all ponds surveyed.

\section{HSI scores vs pond occupancy}

Mean HSI score in the 64 occupied ponds was found to be 0.68 (standard deviation 0.15 ), with HSI scores ranging from 0.28 to 0.93 . This was comparable to 0.63 for the 425 unoccupied ponds (standard deviation 0.17), with scores ranging from 0.19 to 0.98 . Seven of the 64 (10.9 $\%)$ occupied ponds had an HSI score below 0.5 suggesting pond quality was 'Poor'; 10/64 (15.6\%) were of 'Below Average' pond quality; 12/64 (18.8\%) were of 'Average' pond quality; $21 / 64$ (32.8\%) were of 'Good' pond quality; and $14 / 64$ (21.8 \%) were of 'Excellent' pond quality. This was comparable to ponds with unconfirmed occupancy, where 95 of 425 (22.4\%) had an HSI score below 0.5 indicating 'Poor' pond quality; 78/425 (18.4\%) were of 'Below Average' pond quality; 85/425 (20.0\%) were of 'Average' pond quality; 98/425 (23.1\%) were of 'Good' pond quality; and 69/425 (16.2 \%) were of 'Excellent' pond quality (Fig. 2). 


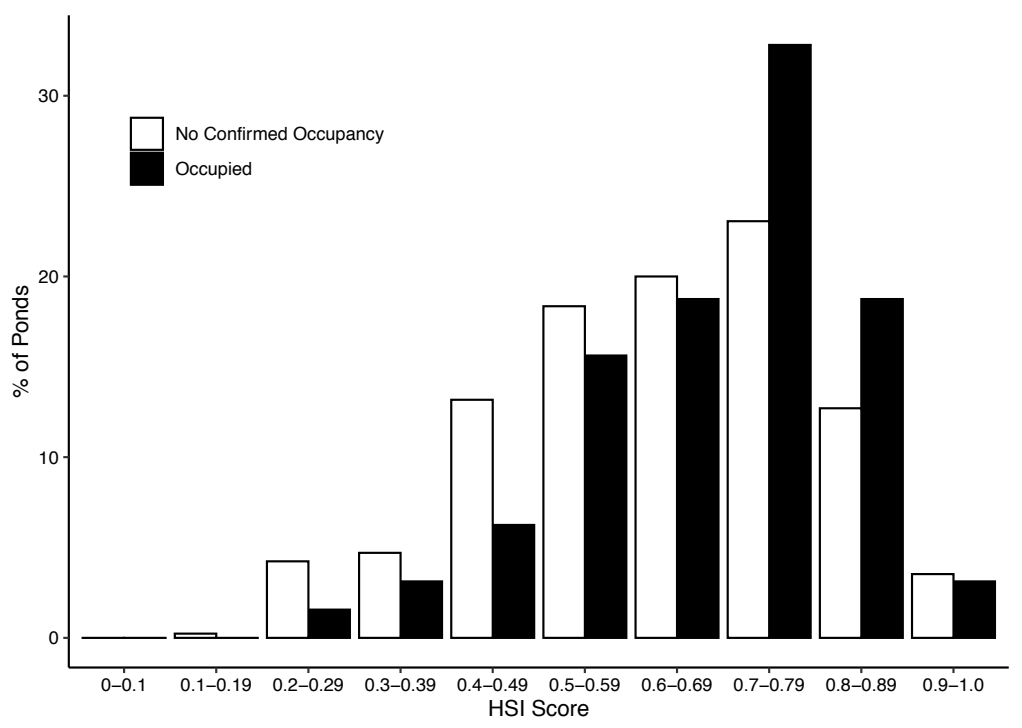

Figure 2. Percentage of occupied ponds (black) and ponds with no confirmed occupancy (white) at each 0.1 increments on the HSI Scale.

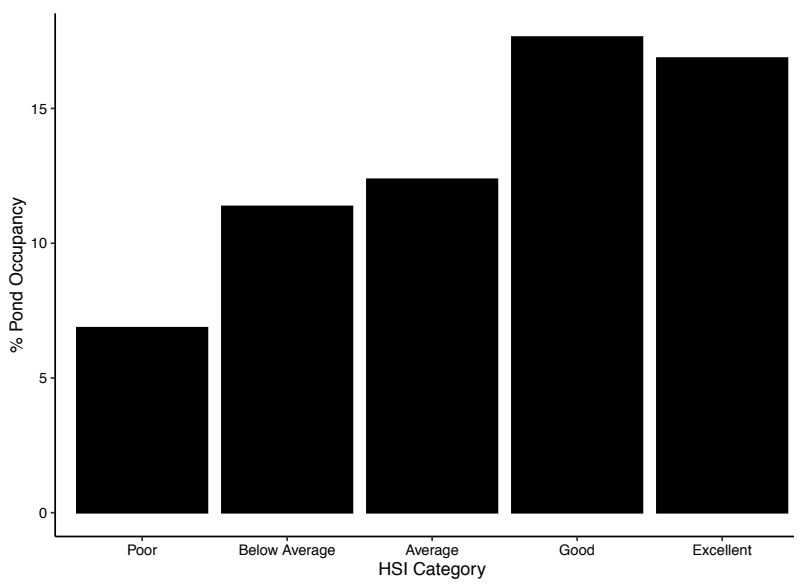

Figure 3. Percentage of occupied ponds for great crested newts within each HSI category.

Correspondingly, 7/102 (6.9\%) of 'Poor' ponds were occupied, 10/88(11.4\%) 'Below Average' ponds occupied, 12/97 (12.4\%) 'Average' ponds were occupied, 21/119 (17.6\%) 'Good' ponds were occupied, and 14/83 (16.9\%) 'Excellent' ponds were occupied (Fig. 3). Consequently, there is a slight increase in pond occupancy in the more favourable HSI categories. A general linear model was used to assess whether pond occupancy by great crested newts was related to HSI score, and a slight positive significant relationship was identified $(\mathrm{df}=491, \mathrm{t}=2.06$, $p=0.04$; Fig. 4).

\section{Covariate analysis}

We examined the individual effects of the ten HSI predictor variables on predicting pond occupancy. The model with the greatest AIC support was found to only include waterfowl and fish as covariates; however, an additional nine models fell within $<2$ delta AIC units of the top model (Table S1). Further analysis was undertaken on cumulative AIC importance weights for

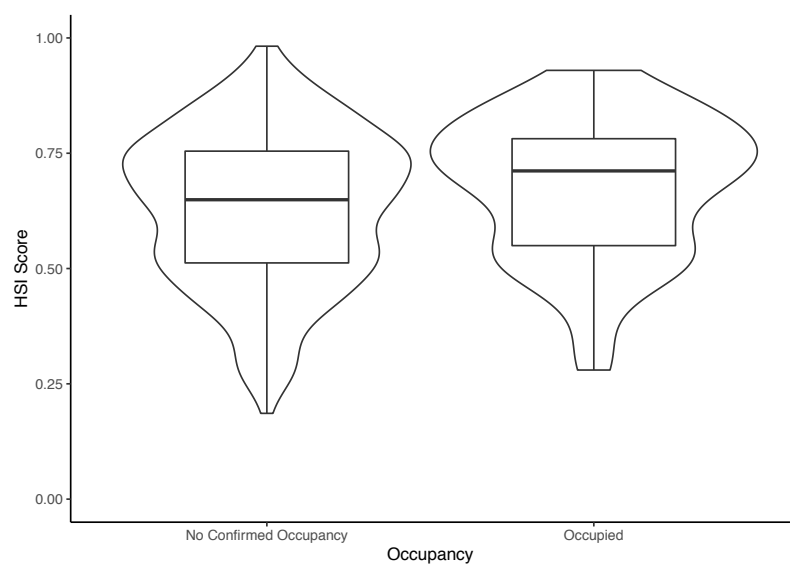

Figure 4. Great crested newt occupancy compared to the overall HSI score. Occupancy taken from the combined naïve eDNA and direct observational survey results, ( $n=489)$.

each of the HSI covariates with waterfowl presence (cumulative AIC weight $=0.8734$ ) strongly supported by the analyses as an important covariate. Fish presence was of secondary importance (cumulative AIC weight = 0.7216 ), with shade (cumulative AIC weight $=0.4611$ ) having less support. Geographic location, pond area, pond count, macrophyte cover, water quality, pond permanence and terrestrial habitat quality each had a cumulative AIC weighting of $<0.4$. However, there was very little significance within the model with the greatest AIC support. The only covariate to show any significance was the "Minor" category for waterfowl presence ( $\mathrm{df}=$ 485; $\mathrm{t}$-value $=2.276 ; \mathrm{p}$-value $=0.0233$ )

\section{DISCUSSION}

The naïve pond occupancy identified in this data set (0.13) is low when compared to other published occupancy rates for great crested newts in the UK. Sewell et al. (2010) found a naïve occupancy rate for both south- 
east England and parts of Wales to be approximately 0.3 . However, the results of this study are closer to the naïve national estimates of between $13 \%$ and $18 \%$ from the Freshwater Habitats Trust PondNet study (Ewald, 2018). The naïve occupancy estimates found in this data set suggest that the study area is more in line with the national average than some previous estimates from high-density areas such as south-east England.

These data show that ponds with a higher HSI score are more likely to be occupied, but there is considerable overlap in scores for ponds with and without confirmed occupancy. Ponds with no confirmed occupancy were found to score as high as 0.98 , while ponds with a score as low as 0.23 were found to be occupied. The use of pond categories may be useful for presenting results to a non-ecological audience; however, this simplification may be leading to misinterpretation and overreliance on the $\mathrm{HSI}$ as an indicator of presence-absence. The use of an $\mathrm{HSI}$ score to predict whether a pond will be occupied or not is therefore unwise.

It has been argued - and accepted by some planning authorities - that ponds with low HSI scores can be ruled out for occupancy assessments. Examples of this can be found within planning applications to Aylesbury Vale District (application number 19/00909/ APP), Milton Keynes Council (application number 20/01134/FUL), Bedford Borough Council (application number 20/00289/FUL) and Tewksbury District Council (application number P0156/20/FUL) as well as others. However, the HSI was never intended to be used as a surrogate for pond occupancy, but was intended as a risk register of potential great crested newt presence, identifying ponds with appropriate habitat. Here we see that seven of the 102 ponds (7\%) in the 'Poor' category $(\mathrm{HSI}<0.5)$ were occupied. Although this is lower than the overall occupancy rate of $13 \%$, we do not consider it to be sufficiently lower to justify ruling out follow-up occupancy assessments. As occupancy at low HSI scores have been observed both by this study and Harper et al. (2019), it would be unwarranted to assume absence from a low HSI score. Nevertheless, we did not observe any occupancy below an HSI of 0.2.

An HSI value of 0.7 or above ('Good' or 'Excellent' categories) has been arbitrarily used as a cut-off to designate likely breeding habitat (Burgess, 2020; Nature Space Partnership, 2019). This is harder to assess using environmental DNA as the method does not differentiate between life stages. The mean HSI for positive ponds was found to be 0.68 with a standard deviation of 0.151 , where 35 of 64 (55\%) ponds fell into the 'Good' or 'Excellent' categories. In certain circumstances, a cutoff value of 0.7 may therefore be argued as appropriate to define potentially important ponds for great crested newts, but with only $21 \%$ of these ponds occupied, it should still not be used to assume occupancy. Similarly, potential occupancy and breeding should not be ruled out in ponds regarded as being less important as almost half of occupied ponds $(N=29: 45 \%)$ in this study had an $\mathrm{HSI}$ score lower than 0.7 .

It is evident from these data that both eDNA and observational methodologies for assessing pond occupancy have associated rates of sampling error.
Where both eDNA and observational survey methods were used on the same ponds, the results concurred 76 $\%$ of the time. Five instances of ponds were found to be negative in the eDNA survey results but positive using observational methods, and fifteen instances where ponds were negative using observational methods but positive for the eDNA survey. Both observational and eDNA survey methods can suffer from false negative error, but the eDNA technique may be subject to false positive error as well (Ficetola et al., 2015; Griffin et al., 2020; Guillera-Arroita et al., 2017). A way of quantifying this error is needed to aid in the interpretation of large data sets. A recent publication by Griffin et al. (2020), develops statistical models to identify error rates in eDNA studies, both at the sample collection stage and in the laboratory. The application of modelling to generate error rates will allow confidence levels to be applied to the data. eDNA analysis has a further limitation in that only presence or likely absence data can be generated, whereas some degree of abundance estimate can be generated from observational surveys. This being said, a large-scale assessment of pond occupancy covering hundreds of ponds would be logistically unfeasible using observational methods, whereas eDNA surveys allows for regional or countrywide assessments to be undertaken with relative ease.

The HSI score takes the geometric mean of ten pond level variables which are easily collected within the field (Oldham et al., 2000). The use of the geometric mean leaves all ten equally weighted within the overall HSI score. It is highly unlikely that all ten will be equally important in determining suitability of ponds for great crested newts. Using logistic regression and cumulative importance weights we attempted to look at each of the covariates in terms of their importance to great crested newt occupancy. Within this data set only waterfowl and fish presence were found to be important individually. Waterfowl - particularly at high densities - tend to reduce water quality, increase the turbidity of water and reduce vegetation (Edgar \& Bird, 2006; Oldham et al., 2000). In addition to increasing turbidity and removal of submerged vegetation, fish also act as direct predators on great crested newt eggs and larvae (Denoël et al., 2013; Edgar \& Bird, 2006; Hartel et al., 2010; McLee \& Scaife, 1992; Oldham et al., 2000; Rannap et al., 2009a, 2009b; Skei et al., 2006). It is possible the other covariates are correlated and become important in certain combinations, or in different landscapes other variables dominate (Harper et al., 2020). For example, in species distribution modelling within the south of England, pond density has been found to be the strongest predictor of great crested newt distribution (Bormpoudakis et al., 2016). As such, the importance weights presented here may not be universally applicable, with local conditions influencing covariate importance.

In conclusion both eDNA and observational surveys suffer from sampling error and this needs to be acknowledged in the analysis of any great crested newt occupancy assessment. We have found no evidence to support the use of low HSI scores as a justification to rule out direct occupancy assessment. However, there is some justification for the use of high HSI scores to 
identify ponds that are potentially important for great crested newts.

\section{Author Contributions}

Hannah Tracey organised and helped to carry out the field surveys and helped tabulate the resulting data. Nick Downs helped to carry out the field surveys and drafted a basic initial manuscript. Andrew Buxton wrote the majority of the final manuscript and carried out the data analysis.

\section{Ethics statement}

The data was collected as part of a commercially commissioned great created newt distribution assessment, which was subsequently made available for this analysis. This analysis caused no additional survey or disturbance to ponds or target species. All surveys were undertaken by suitably trained and licenced surveyors following national standard protocols.

\section{Data availability}

Raw data is available as a supplementary excel data file "Table S2 Raw Data". R code is hosted on OSF at the following link: https://osf.io/uk84t/?view_only=31da01f 779cc4c408dffad490eba5eb0

\section{ACKNOWLEDGEMENTS}

A significant number of people and organisations were involved with this project, to which the authors owe a large debt of gratitude. Although it is not possible to name everyone, of particular note was the project management provided by Nick Henson. The ecologists involved in the survey work presented in this paper were employed by Arcadis, working on behalf of the National Grid. Thanks are due to the National Grid for allowing publication. We would like to thank Richard Griffiths and Jim Foster for constructive comments on an earlier version of the manuscript and NatureSpace Partnership for providing planning application examples. We would like to thank two anonymous reviewers whose comments improved the manuscript.

\section{REFERENCES}

Allen, A. W. \& Hoffman, R. D. (1984). Habitat suitability index models: Muskrat.

ARG UK. (2010). ARG UK Advice Note 5: Great Crested Newt Habitat Suitability Index.

ARG UK. (2017). ARG UK Advice Note 4 Amphibian disease precautions : a guide for UK fieldworkers.

Baker, J., Beebee, T., Buckley, J., Gent, T., Orchard, D., Bennett, A., Bernhard, T., Brady, L., Coward, D., Driver, B., Foster, J., Gleed-Owen, C., Herder, J. et al. (2011). Amphibian habitat management handbook. Amphibian and Reptile Conservation.

Biggs, J., Ewald, N., Valentini, A., Gaboriaud, C., Dejean, T., Griffiths, R., Foster, J., Wilkinson, J., Arnell, A., Brotherton, P., Williams, P. \& Dunn, F. (2015). Using eDNA to develop a national citizen science-based monitoring programme for the great crested newt (Triturus cristatus). Biological Conservation 183, 19-28.
Biggs, J., Ewald, N., Valentini, A., Gaboriaud, C., Griffiths, R., Foster, J., Wilkinson, J., Arnett, A., Williams, P. \& Dunn, F. (2014). Analytical and methodological development for improved surveillance of the great crested newt Appendix 5. Technical advice note for field and laboratory sampling of great crested newt (Triturus cristatus) environmental DNA.

Bormpoudakis, D., Foster, J., Gent, T., Griffiths, R. A., Russell, L., Starnes, T., Tzanopoulos, J. \& Wilkinson, J. (2016). Developing models to estimate the occurrence in the English countryside of great crested newts, a protected species under the Habitats Directive. Defra Project WC1108.

Burgess, K. (2020). Monitoring and Evaluation of the Environmental outcomes of District level Licensing for great crested newts.

Buxton, A. S., Groombridge, J. J. \& Griffiths, R. A. (2018). Seasonal variation in environmental DNA detection in sediment and water samples. PLOS ONE 13, e0191737.

Buxton, A. S., Groombridge, J. J., Zakaria, N. B. \& Griffiths, R. A. (2017). Seasonal variation in environmental DNA in relation to population size and environmental factors. Scientific Reports 7, 46294.

Calcagno, V. \& de Mazancourt, C. (2010). gImulti: An R package for easy automated model selection with (generalized) linear models. Journal of Statistical Software 34(12), 29.

Cresswell, W. J. \& Whitworth, R. (2004). An assessment of the efficiency of capture techniques and the value of different habitats for the great crested newt Triturus cristatus. In English Nature (Issue 576).

Denoël, M., Perez, A., Cornet, Y. \& Ficetola, G. F. (2013). Similar Local and Landscape Processes Affect Both a Common and a Rare Newt Species. PLOS ONE 85, e62727.

Edgar, P. \& Bird, D. R. (2006). Action Plan for the conservation of the crested newt Triturus cristatus species complex in Europe - Convention on the Conservation of European Wildlife and Natural Habitats. Standing Comittee, 26th meeting, Strasbourg, 27-30 November 2006.

English Nature. (2001). Great crested newt mitigation guidelines. English Nature.

Ewald, N. (2018). eDNA monitoring for great crested newts 2018. https://freshwaterhabitats.org.uk/wp-content/ uploads/2019/04/eDNA-Great-Crested-Newt-2018.pdf

Ficetola, G. F., Pansu, J., Bonin, A., Coissac, E., Giguet-Covex, C., De Barba, M., Gielly, L., Lopes, C. M., Boyer, F., Pompanon, F., Rayé, G. \& Taberlet, P. (2015). Replication levels, false presences and the estimation of the presence/absence from eDNA metabarcoding data. Molecular Ecology Resources 15, 543-556.

Griffin, J. E., Matechou, E., Buxton, A. S., Bormpoudakis, D. \& Griffiths, R. A. (2020). Modelling environmental DNA data; Bayesian variable selection accounting for false positive and false negative errors. Journal of the Royal Statistical Society. Series C: Applied Statistics 69, 377-392.

Griffiths, R.A., Raper, S. J. \& Brady, L. D. (1996). Evaluation of a standard method for surveying common frogs (Rana temporaria) and newts (Triturus cristatus, T. helveticus and T. vulgaris). In JNCC Report No. 259.

Griffiths, Richard A. \& Inns, H. (1998). Surveying. In T. Gent \& S. Gibson (Eds.), Herpetofauna Workers' Manual. Joint Nature Conservation Committee.

Guillera-Arroita, G., Lahoz-Monfort, J. J., van Rooyen, A. R., Weeks, A. R. \& Tingley, R. (2017). Dealing with false positive 
and false negative errors about species occurrence at multiple levels. Methods in Ecology and Evolution 8, 10811091.

Harper, L. R., Buxton, A. S., Rees, H. C., Bruce, K., Brys, R., Halfmaerten, D., Read, D. S., Watson, H. V., Sayer, C. D., Jones, E. P., Priestley, V., Mächler, E., Múrria, C. et al. (2018). Prospects and challenges of environmental DNA (eDNA) monitoring in freshwater ponds. Hydrobiologia 5.

Harper, L. R., Downie, J. R. \& McNeill, D. C. (2019). Assessment of habitat and survey criteria for the great crested newt (Triturus cristatus) in Scotland: a case study on a translocated population. Hydrobiologia 828, 57-71.

Harper, L. R., Lawson Handley, L., Hahn, C., Boonham, N., Rees, H. C., Lewis, E., Adams, I. P., Brotherton, P., Phillips, S. \& Hänfling, B. (2020). Generating and testing ecological hypotheses at the pondscape with environmental DNA metabarcoding: A case study on a threatened amphibian. Environmental DNA 2, 184-199.

Hartel, T., Nemes, S., Óllerer, K., Coglniceanu, D., Moga, C. \& Arntzen, J. W. (2010). Using connectivity metrics and niche modelling to explore the occurrence of the northern crested newt Triturus cristatus (Amphibia, Caudata) in a traditionally managed landscape. Environmental Conservation 37, 195-200.

Inns, H. (2009). Britain's Reptiles and Amphibians : A Guide to the Reptiles and Amphibians of Great Britain, Ireland and the Channel Islands. WILDGuides.

Jane, S. F., Wilcox, T. M., Mckelvey, K. S., Young, M. K., Schwartz, M. K., Lowe, W. H., Letcher, B. H. \& Whiteley, A. R. (2015). Distance, flow and PCR inhibition: eDNA dynamics in two headwater streams. Molecular Ecology Resources 15, 216227.

Jehle, R. \& Arntzen, J. W. (2000). Post-breeding migrations of newts (Triturus cristatus and T. marmoratus) with contrasting ecological requirements. Journal of Zoology 251, 297-306.

Langton, T. E. S., Beckett, C. L. \& Foster, J. P. (2001). Great crested newt conservation handbook. In Froglife. Froglife.

Marchetti, M. P., Light, T., Moyle, P. B. \& Viers, J. H. (2004). Fish invasions in California watersheds : testing hypotheses using landscape patterns. Ecological Applications 14, 15071525.

McLee, A. G. \& Scaife, R. . (1992). The colonisation by great cersted newts (Triturus cristatus) of a waterbody following treatment with a piscicide to remove large populaions of sticklebakcs (Gasterosteus aculeatus). British Herpetological Society Bulletin 42, 6-9.

Natural England. (2015). Guidance: Great crested newts: surveys and mitigation for development projects. https:// www.gov.uk/guidance/great-crested-newts-surveys-andmitigation-for-development-projects

Nature Space Partnership. (2019). NatureSpace Partnership. 2019. South Midlands region extension GCN District Licensing project Implementation Strategy.

Oldham, R. S., Keeble, J., Swan, M. J. S. \& Jeffcote, M. (2000). Evaluating the suitability of habitat for the great crested newt (Triturus cristatus). Herpetological Journal 10, 143155.
Pondnet. (2013). How to collect a water sample to detect great crested newt eDNA Sampling the pond. Protocol, 1-4.

R-Core Team. (2020). R: language and environment for statistical computing. R Foundation for Statistical Computing.

Rannap, R., Lõhmus, A. \& Briggs, L. (2009a). Niche position, but not niche breadth, differs in two coexisting amphibians having contrasting trends in Europe. Diversity and Distributions 15, 692-700.

Rannap, R., Lõhmus, A. \& Briggs, L. (2009b). Restoring ponds for amphibians: A success story. Hydrobiologia 634, 87-95.

Rees, H. C., Bishop, K., Middleditch, D. J., Patmore, J. R. M., Maddison, B. C. \& Gough, K. C. (2014). The application of eDNA for monitoring of the great crested newt in the UK. Ecology and Evolution 4, 4023-4032.

Sewell, D., Beebee, T. J. C. \& Griffiths, R. A. (2010). Optimising biodiversity assessments by volunteers: The application of occupancy modelling to large-scale amphibian surveys. Biological Conservation 143, 2102-2110.

Sewell, D., Griffiths, R. A., Beebee, T. J. C., Foster, J. \& Wilkinson, J. W. (2013). Survey protocols for the British herpetofauna Version 1.0 (Issue March). http://www.narrs. org.uk/documents/Survey_protocols_for_the_British_ herpetofauna.pdf

Skei, J., Dolmen, D., Rønning, L. \& Ringsby, T. (2006). Habitat use during the aquatic phase of the newts Triturus vulgaris (L.) and T. cristatus (Laurenti) in central Norway: proposition for a conservation and monitoring area. Amphibia-Reptilia 27, 309-324.

Thomsen, P. F., Kielgast, J., Iversen, L., Wiuf, C., Rasmussen, M., Gilbert, M. T. P., Orlando, L. \& Willerslev, E. (2012). Monitoring endangered freshwater biodiversity using environmental DNA. Molecular Ecology 21, 2565-2573.

Thomsen, P. F. \& Willerslev, E. (2015). Environmental DNA An emerging tool in conservation for monitoring past and present biodiversity. Biological Conservation 183, 4-18.

U.S. Fish and Wildlife Service. (1976). Habitat Evaluation Procedures ESM 101.

U.S. Fish and Wildlife Service. (1980). Habitat Evaluation Procedures (HEP) ESM 102.

U.S. Fish and Wildlife Service. (1981). Standards for the development of habtiat suitability inidex models for use in teh habitat evaluation procedures (HEP).

Unglaub, B., Steinfartz, S., Drechsler, A. \& Schmidt, B. R. (2015). Linking habitat suitability to demography in a pondbreeding amphibian. Frontiers in Zoology 12, 9.

Wesche, T. A., Goertler, C. M. \& Hubert, W. A. (1987). Modified Habitat Suitability Index Model for Brown Trout in Southeastern Wyoming. North American Journal of Fisheries Management 7, 232-237.

Wielstra, B., McCartney-Melstad, E., Arntzen, J. W., Butlin, R. K. \& Shaffer, H. B. (2019). Phylogenomics of the adaptive radiation of Triturus newts supports gradual ecological niche expansion towards an incrementally aquatic lifestyle. Molecular Phylogenetics and Evolution 133, 120-127.

Accepted: 1 February 2021 